\title{
A MULHER NO LIVRO DIDÁTICO DE GEOGRAFIA: REPRESENTAÇÕES, IMAGENS E DISCURSO
}

\author{
Mariana Brockes Campos ${ }^{1}$ \\ Rusvênia Luiza Batista Rodrigues ${ }^{2}$
}

\begin{abstract}
Resumo: $\mathrm{O}$ presente artigo avaliará o lugar da mulher no livro didático de Geografia. Será analisada a última aprovação de livros realizada pelo PNLD (Plano Nacional do Livro Didático), cujas obras já foram distribuídas e utilizadas nas escolas, ou seja, a de 2014. Foram analisadas duas coleções de Geografia do Ensino Fundamental II, selecionadas de acordo com o critério de terem sido as mais distribuídas no Brasil pelo PNLD. O lugar da mulher no livro didático de Geografia se dará por uma análise das representaçóes, imagens e discurso identificados nos livros didáticos em questão. Percebeuse que, ao longo da análise, a mulher tem ocupado lugar estereotipado sendo ainda incipientes as açôes desempenhadas com o objetivo de uma representação totalizante e mais ampliada do seu lugar na sociedade-mundo.
\end{abstract}

Palavras-chave: Geografia escolar; Livro didático; Mulher.

\section{THE WOMAN IN THE TEXTBOOK OF GEOGRAPHY: REPRESENTATIONS, IMAGES AND SPEECH}

\begin{abstract}
The present article will evaluate the place of the woman in the textbook of Geography. It will be analyzed the last books approved by PNLD (National Plan of the Didactic Book), whose works have already been distributed and used in schools, that is, the one of 2014. Two collections of Geography of Elementary School II, selected according to the criterion of having been the most distributed in Brazil by PNLD. The place of the woman in the textbook of Geography will be given by an analysis of the representations, images and speech identified in the textbooks in question. It was noticed that, throughout the analysis, the woman has occupied stereotyped place being still incipient the actions carried out with the objective of a totalizing and amplified representation of its place in the world-society.
\end{abstract}

Keywords: School geography. Textbook. Womam.

1 Graduada em Geografia pela Universidade Federal de Goiás (UFG).

2 Graduada em Geografia pela Universidade Federal de Goiás (UFG), mestre pela Universidade Estadual Paulista Júlio de Mesquita Filho e doutora pela Universidade de São Paulo. É professora Associada I da Universidade Federal de Goiás. 


\section{Introduçáo}

Este trabalho é movido pela necessidade que encontramos de tematizar a questão da mulher na escola. Os motivos que nos fizeram levantar essa questão se relacionam à percepção de que se trata de um tema pouco abordado nas escolas, nas universidades e em toda a sociedade, mesmo diante de diversos aspectos que nos afrontam cotidianamente e que demonstram o quanto o tema deve ser discutido, refletido e disseminado, da maneira mais abrangente possível.

A educação como a conhecemos é de grande relevância para a formação e manutenção da sociedade. Pensar nos problemas sociais pode ser, muitas vezes, pensar na forma como a organização das instituições formadoras dos indivíduos e, em específico, as instituições de ensino, tratam as diversas temáticas sociais, ou seja, os processos de educação. Nossa intenção neste artigo é problematizar a relação entre educação e cultura e, mais especificamente, analisar um tema: a representação social da mulher no material didático mais popular da escola, o livro, dentro da disciplina de Geografia.

A palavra educação nos leva a vários tipos de reflexão bem como também nos conduz a pensar em escola, lócus material onde a educação se manifesta socialmente e institucionalmente. Ao pensar em escola nos conduzimos a uma série de outros pensamentos e elementos que a rodeiam. Um desses elementos é o livro didático, um instrumento elementar de síntese da Geografia escolar. É um instrumento que, possivelmente, está entre os mais representativos do universo cotidiano de muitas escolas brasileiras. Sua importância, muitas vezes, pode ser até questionada (e deve, uma vez que há muitas relações de força por detrás da produção desse material); porém, podemos repensar o foco desse questionamento, se considerarmos que existe um Programa Nacional do Livro Didático (PNLD) a partir do qual está organizada a distribuição dos livros didáticos a todas as escolas públicas e aos estudantes dessas escolas, em todo o território brasileiro, independentemente da região ou classe social.

O questionamento pretendido aqui diz respeito às mensagens que os livros didáticos podem trazer acerca da representação socioespacial da mulher e, também, se essa representação está apenas nas discussões que a Geografia escolar e cultural está fazendo no campo acadêmico, de modo, a saber, se estão contempladas no livro didático. O livro didático pode ser um importante material no processo de ensinoaprendizagem; pretende-se averiguar a maneira como comparecem certos temas que cruzam questões sobre o feminino, a pensar como esse tipo de abordagem pode contribuir para o questionamento de problemas sociais.

As representações socioespaciais que procuramos aprofundar neste artigo são aquelas relacionadas à/às mulher/mulheres. Chamaremos de representações as mensagens transmitidas pelo livro didático que retrata a mulher. Denominamos assim porque analisamos como o livro didático de Geografia representa/reproduz a mulher em suas páginas, seja em imagens, espacializações e/ou discursos. Procuramos pensar, também, a representatividade, ou seja, qual é a natureza do espaço dedicado às mulheres, quantitativa e qualitativamente. 
Os livros didáticos são elaborados por pessoas que estão inseridas na sociedade brasileira. Sociedade esta que, como já colocado aqui, possui problemas. Partindo do pressuposto de que a neutralidade é algo utópico e que, de acordo com o pesquisador Japiassu (1975), não existe neutralidade científica, as pessoas que produzem os livros (escritoras, editoras, etc) não são neutros e carregam valores e concepções de mundo e sociedade que, consequentemente, estão presentes nos livros didáticos que consumimos. Tal movimento pode ser responsável por reforçar questões sociais como diversas formas de preconceito. Um desses problemas sociais está relacionado às manifestações diversas de sexismo e machismo, os quais serão observados em nossa pesquisa documental nos livros, selecionando as duas coleções mais distribuídas no Brasil, de $7^{\circ}$ ao $9^{\circ}$ ano, da segunda fase do Ensino Fundamental.

A partir disso elaboramos as seguintes interrogações, que guiaram o estudo: Como a mulher está representada no livro didático de Geografia? De que forma se dá essa representação? Existe alguma discussão de gênero nesses livros? Qual é o espaço dedicado a essa discussão? Como as professoras e as estudantes se veem representadas nos livros? As mulheres ocupam lugar de relevância dentro desses livros? Do ponto de vista da linguagem, há uma tentativa de empregá-la de forma neutra, no que diz respeito ao gênero? A iconografia dos livros didáticos de Geografia representa a mulher? Se sim, de que maneira?

\section{A mulher na Geografia escolar}

Os noticiários, diariamente, nos dão acesso a uma infinidade de acontecimentos que, por revelarem concepções de mundo ultrapassadas, parecem incompatíveis com a época em que vivemos. A tecnologia que nos rodeia pode dublar a nossa percepção e deixar a impressão de uma sociedade evoluída e desenvolvida, mas os acontecimentos que afetam as minorias vêm em direção contrária a essa falsa impressão. Apesar de as mulheres e homens terem direitos e obrigações civis iguais, de acordo com a Constituição brasileira, não se pode dizer que as mulheres experimentem a equidade de gênero no cotidiano.

Trarei, assim, alguns dados sobre renda e a participação das mulheres na política, fundamentando a problematização a respeito da equidade de gênero: Cerca de $60 \%$ das mulheres possuem ensino superior completo contra $40 \%$ dos homens, mesmo com esses dados, em média as mulheres recebem $27,25 \%$ a menos que os homens. Dentre os 50\% mais ricos apenas 34\% são mulheres, e dentre os $1 \%$ mais ricos apenas 28\% são mulheres (IBGE, 2010). As mulheres representam apenas $8,6 \%$ na câmara de deputados e $16 \%$ no senado (União Inter-Parlamentar). Isto significa que do ponto de vista da renda e da participação política, as mulheres ainda não usufruem de um tratamento igualitário. Deparamo-nos, constantemente, com situações de violência.

As mulheres, em especial, costumam estar mais suscetíveis a esses episódios violentos. Alguns dados ilustram brevemente a gravidade da situação a que as mulheres estão expostas. Alguns exemplos disso: "Estudo revela que a cada $1 \mathrm{~h} 30$ 
ocorre um feminicídio no Brasil", " $29 \%$ dos feminicídios ocorreram no domicílio e 31\% em via pública" (Ipea, 2013), "Taxa de feminicídio no Brasil é a $5^{\circ}$ maior do mundo" (OMS, 2015). O feminicídio, conforme o Relatório final, CPMI-VCM (2013) é a "[...] instância última de controle da mulher pelo homem: o controle da vida e da morte". Bandeira, (2013) declara que "Feminicídio é o assassinato de uma mulher pela condição de ser mulher [...] representa a última etapa de um continuum de violência". Desse modo, o feminicídio, aqui, é entendido como a última etapa da violência contra a mulher que, antes da morte, é exposta a diversas outras formas de violência.

O machismo e a violência contínua contra a mulher não são sempre explícitos, podendo muitas vezes se manifestar sutil e discretamente. Ambos mostram-se nas entrelinhas do cotidiano, na desigualdade salarial; na baixa representação no Legislativo e em outros cargos do governo ou empresas; nas interrupções de fala (comportamento conhecido como manterrupting); em situações que são nomeadas como e mansplaining, bropriating, gaslighting; na linguagem, em que há predominância do uso de palavras masculinas tidas como neutras; na representação das mulheres na mídia; e na quantidade de vezes em que mulheres aparecem nas bibliografias básicas das disciplinas de cursos de graduação.

De que maneira nossa disciplina pode contribuir para tematizar a questão? Como a mulher tem estado nas discussões, nos livros e nos conteúdos de Geografia? O porquê de se tomar a mulher como objeto de estudo é claro, diante de incontáveis fatos que descortinam uma sociedade estruturalmente machista. Devemos, assim, pensar em como trazer essa discussão para a Geografia, como conteúdo acadêmico aplicado ao ensino e ao livro didático. A Geografia é uma área de estudo abrangente, complexa e crítica. José Bueno Conti (1997) a coloca como a mais abrangente e singular das ciências, sendo seus limites os da inteligência, e seus horizontes, infinitos. Portanto, o machismo presente na sociedade pode e deve ser estudado por essa ciência. Para Silva

A Geografia, de uma maneira geral, tem considerado a sociedade como um conjunto neutro, assexuado e homogéneo. [...] Entendido que o espaço não é neutro do ponto de vista do gênero, torna-se necessário incorporar as diferenças sociais entre mulheres e homens e as diferenças territoriais nas relações de género. (1998, p.108)

Apreendemos, com essa afirmação, que a Geografia não se encontra dissociada das questões de gênero. Pelo contrário, a ciência geográfica é constituída por relações de gênero, o que legitima o estudo dessas relações. Para maior aprofundamento e fundamentação teórica, trago a reflexão de Martínez (1995) de que na Geografia existem três grandes áreas em que o estudo de gênero é fundamental. São elas:

As relações existentes entre gênero e conceitos chaves na Geografia como são o espaço, o lugar e a natureza; - o espaço enquanto constructo social e de gênero, - o conceito de lugar e a importância que em sua definição introduzem as diferenças de gênero - a relação entre gênero e natureza (o meio ambiente em seu sentido amplo); - As diferenças territoriais nos papéis e relações de 
gênero; $\mathrm{O}$ uso e experiência diferenciais do espaço entre homens e mulheres, em distintas escalas: desde a escala local (utilização do espaço cotidiano, por exemplo) a global (movimentos migratórios transnacionais). (1995, p.18)

A partir das violências sofridas pela mulher, podemos problematizar seu lugar na cidade, e o poder que ela exerce ou que é exercido sobre ela, dentro do território brasileiro. Falar sobre o poder e o território (simbólico ou não) da mulher é falar em Geografia, e falar em Geografia é falar das relações e inter-relações das pessoas com/no espaço.

Pode-se, em vista disso, afirmar que a mulher se encontra em situação desprivilegiada, na realidade brasileira. É pertinente atentar para a forma como poderíamos trabalhar na tentativa de modificar esse cenário. Pensando assim, a Geografia escolar vem como uma possibilidade de caminho para esta tentativa, pensando-a como conjunto amplo de conhecimentos cujo objetivo é a formação acadêmica na educação básica de modo a contribuir significativamente para a sociedade. Sendo a escola um ambiente de fomento à criticidade e de formação cidadã, ela se configura como um espaço apropriado para se empregar esforços em direção a uma sociedade mais igualitária.

O PCN-Geografia (1998, p. 60) propõe alguns eixos temáticos. Entre eles, estão: "[...] a Geografia como uma possibilidade de leitura e compreensão do mundo; o mundo como uma pluralidade de lugares interagindo entre si; a cidadania como a consciência de pertencer e interagir e sentir-se integrado com pessoas e os lugares.". Desta forma, vemos que o ensino de Geografia pode estar interligado e aberto às questões de gênero, se assim quisermos. Ainda no PCN-Geografia, a discussão de gênero é abordada de maneira mais direta: "Situar em um mesmo patamar os papéis desempenhados por homens e mulheres na construção da sociedade contemporânea que ainda encontra barreiras que ancoram expectativas bastante diferenciadas com relação ao papel futuro de meninos e meninas.” (p.45). O trecho evidencia que no ensino de Geografia há espaço para questões de gênero, assunto de fundamental relevância na compreensão moderna de mundo.

Explicitada a pertinência do debate sobre questões de gênero na sociedade, na Geografia e no ensino de Geografia, coloco em foco a relevância dessa discussão dentro dos livros didáticos. O livro didático está cercado de controvérsias, mas sua importância é quase sempre reconhecida. Bittencourt (2004) coloca o livro didático como objeto cultural contraditório e gerador de críticas e polêmicas, mas que sempre tem sido considerado como um instrumento fundamental no processo de escolarização. Para Martins (2006, p.124) o livro didático é um artefato cultural, com sua história não desvinculável da própria história do ensino escolar, do aperfeiçoamento das tecnologias de produção gráfica e dos padrões mais gerais de comunicação na sociedade.

Entendendo o livro didático como um dos pilares da escola e da educação brasileira, e considerando que, em determinadas realidades, é o único material de consulta para muitas estudantes e, pesarosamente, para muitas professoras, problematizá-lo pode ser uma das maneiras mais eficazes para trabalhar uma 
alternativa de conceitos e ideais das estudantes. Trabalhar os conceitos e ideais das estudantes pode ser trabalhar os valores da nossa futura sociedade. Conforme anuncia Fernandes (1995), "feita a revolução nas escolas, o povo a fará nas ruas".

Tomando a Geografia como a ciência que o livro didático pretende apresentar para as estudantes, e considerando que um dos ramos em que a Geografia pode se subdividir é a Geografia feminista ou a Geografia de gênero, como cunhado por Silva (1998), o livro didático de geografia deve trazer consigo a discussão de gênero, assim como qualquer outra discussão que perpassa os ramos dessa ciência geográfica.

Em razão de haver ainda uma escassez de estudos sobre a mulher na Geografia e, mais especificamente, no ensino de Geografia e no livro didático de Geografia, um trabalho desta natureza se mostra necessário. Desse modo, a expectativa é a de que este artigo contribua com o debate e forneça condições para que haja um maior aprofundamento na problematização da representação feminina no livro didático de Geografia.

\section{O livro didático}

A construção do livro didático de Geografia está permeada por diversos fatores, dos mais explícitos como o PNLD até os mais implícitos como a influência das editoras e da sociedade em seu conteúdo. Para a autora, os livros didáticos estão inseridos em uma cadeia, tanto no que diz respeito ao uso quanto à produção. Para ilustrar melhor este pensamento, trago, a seguir, um esquema mental de autoria própria:

Figura 1 - Sistema Conceitual

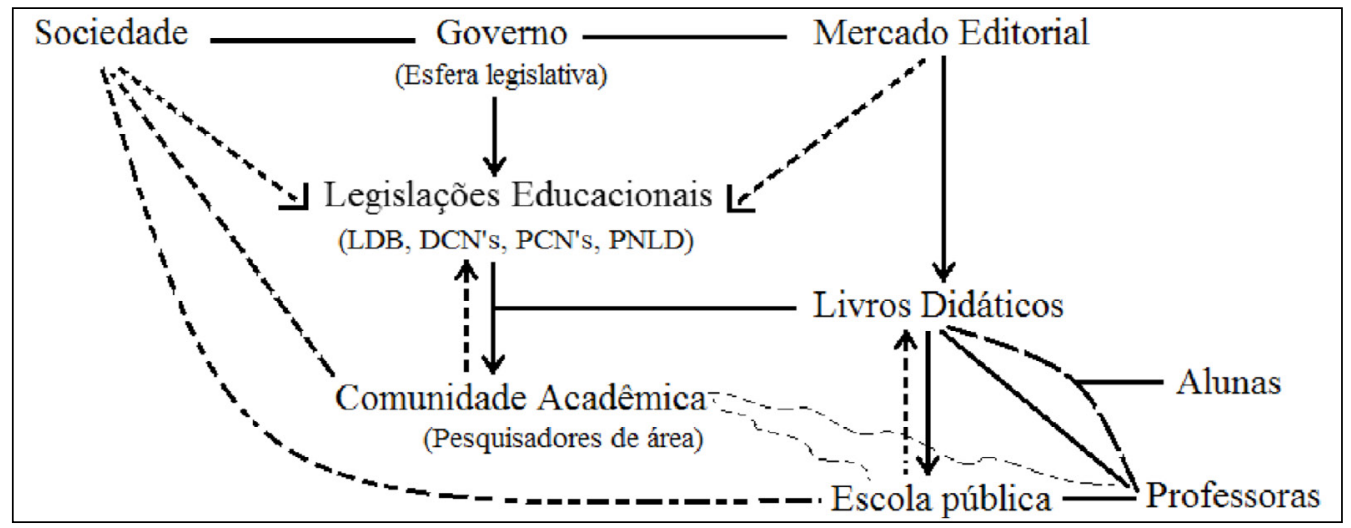

Org. CAMPOS, Mariana Brockes (2017)

Neste esquema mental, podemos identificar três tipos de linhas que fazem a conexão entre os conceitos, uma ininterrupta que representa a relação direta, uma pontilhada que significa uma relação indireta e outra curva e pontilhada, que 
pode-se dizer, que há pouca conexão, mas não nula. As setas representam o sentido hierárquico da ligação, e a linha sem a seta demonstra uma ligação mais horizontal.

Tentarei trazer uma breve explicação de como compreendo este sistema de conexões; o Governo está como figura central, porque vivemos em um país que possui forte intervenção estatal na educação, mesmo tendo sua figura como central está no mesmo patamar que a sociedade e o mercado editorial. A sociedade, ao menos em teoria, compõe o governo, o elege, e possui seus interesses governados por ele. O mercado editorial também está no mesmo patamar, por já representar menos a teoria, como no caso da relação sociedade governo, e mais a realidade. Pode-se dizer que vivemos em um país sob forte influência neoliberal, o que significa que o mercado influencia diretamente o governo, e o mercado editorial não deixa de seguir essa lógica. As legislações educacionais se pautam no mesmo raciocínio, sofrendo influência do mercado editorial e da sociedade. O governo apresenta uma ligação mais direta com essas legislações, já que é ele quem a constrói.

A comunidade acadêmica está correlacionada às legislações, à sociedade, à escola e às professoras. As legislações educacionais agem com hierarquia sobre a academia, já que a comunidade acadêmica segue o que está previsto legalmente para a Educação, porém esta comunidade também influencia as legislações, de maneira indireta. A escola e as professoras, por mais distantes que possam estar das instituições acadêmicas ainda possuem ligação, pois de certa maneira são indissociáveis.

Os livros didáticos são construídos pelo mercado editorial, regulamentados pelas legislações e influenciados pela academia. As professoras selecionam os livros didáticos disponíveis e estes chegam às escolas. As alunas entram em contato com estes materiais didáticos por meio da mediação das professoras, sendo auxiliadas em sua utilização, e também por contato direto, já que é um material individual que se pode levar para casa.

O que regulamenta, atualmente, o livro didático e a educação, de forma oficial, direta ou indiretamente, são a LDB, DCN, PCN, PNLD o PNE. Me aprofundarei mais no PNLD, que está mais diretamente ligado à seleção e distribuição de livros didáticos. Os livros que estão nas escolas públicas são obras que passaram pela aprovação do PNLD, que constrói um edital estabelecendo critérios aos quais as editoras devem se submeter para terem seus respectivos livros aceitos. A cada 3 anos, o edital de um nível de ensino é renovado. Os conteúdos de cada disciplina, nos livros didáticos, devem estar, portanto, de acordo com as recomendações do PNLD, não contrariando os PCN, DCN e a LDB.

\section{A mulher nas legislaçóes educacionais}

Uma vez que a educação e os livros didáticos são coordenados por parâmetros, diretrizes e legislações nos cabe pensar como a mulher está inserida nestes componentes, já que eles são os primeiros norteadores da educação brasileira. Traremos cada um destes documentos separadamente para conseguirmos visualizar melhor nossa problemática. 
Como metodologia, adotaremos a análise do discurso, a partir de três aspectos, se o texto aborda questões de gênero e igualdade de gênero; se o texto possui uma linguagem neutra, em termos de gênero; e se quando se fala sobre humanidade, são utilizados termos neutros ou masculinos.

A LDB, em seu corpo textual, não fala sobre mulheres, traz a palavra "homem" representando a humanidade, além de ter a linguagem no masculino, com intenção de se referir a homens e mulheres. Exemplificarei para melhor compreensão. A frase "zelar pela aprendizagem dos alunos" (LDB, 1996) poderia ser colocada de forma neutra, dos/das alunos/as ou das/dos estudantes.

O DCN, por sua vez, dá certa visibilidade às mulheres, as colocando em foco em algumas partes do texto, destacando a sua importância e a importância da igualdade de gênero. No entanto, mesmo trazendo reflexão sobre a igualdade de gênero, o texto é redigido no gênero masculino e utiliza a palavra "homem" para se referir à humanidade, em grande parte do documento.

O PCN Geografia do $3^{\circ}$ e $4^{\circ}$ ciclo do Ensino Fundamental faz um apontamento sobre a igualdade de gênero. No entanto, devo ressaltar que esse apontamento está situado dentro do tópico "Orientação sexual". Questões de gênero e orientação sexual são coisas completamente distintas. A linguagem do documento está no gênero masculino e há a utilização de "homem" em referência à humanidade.

No edital do PNLD 2014, temos nos princípios gerais uma menção a equidade de gênero. $\mathrm{O}$ documento também se encontra redigido no gênero masculino. No entanto, não se refere à humanidade através do termo "homem".

Uma vez que o intuito deste trabalho é aprofundar-se nas discussões de gênero dentro do livro didático, trago, a seguir, a forma como a discussão de gênero se apresenta no edital do PNLD (2014, p.54):

1. promover positivamente a imagem da mulher, considerando sua participação em diferentes trabalhos, profissões e espaços de poder;

2. abordar a temática de gênero, da não-violência contra a mulher, visando à construção de uma sociedade não-sexista, justa e igualitária, inclusive no que diz respeito ao combate à homofobia;

3. promover a imagem da mulher através do texto escrito, das ilustrações e das atividades das coleções, reforçando sua visibilidade;

No terceiro item existe a proposta de "promover a imagem da mulher através do texto escrito [...] reforçando sua visibilidade". Pode-se questionar como se daria essa promoção através do texto escrito e, também, problematizar se os outros documentos oficiais que regem a educação estão de acordo com essa recomendação ou se ela é ignorada quando se redige um documento no gênero masculino. Tendo em mente que esses documentos são um dos fatores que mais exercem influência na educação brasileira, trabalhar para que se apresentem de forma mais neutra e refletindo equidade é fundamental. 
Diante deste trecho retirado do edital do PNLD (2014), podemos inferir que a proposta para os livros didáticos preocupa-se em tratar da questão da equidade de gênero. Cabe agora analisar os livros didáticos e avaliar se essas propostas estão sendo implementadas satisfatoriamente.

\section{A mulher nos livros didáticos de Geografia}

Os livros selecionados para análise são os mais distribuídos no PNLD de 2014, que são as coleções: Projeto Araribá e o Expedições Geográficas. Dessas coleções, foram analisados os livros do $7^{\circ}$ ao $9^{\circ}$ ano, uma vez que são nesses anos que se formam as primeiras ideias conceituais das disciplinas ministradas, e ocorrem alguns dos primeiros contatos com os conhecimentos científicos sistematizados.

A análise partirá de uma perspectiva da imagética na qual a mulher está sendo representada dentro destes livros. Como ela está posta, o que é falado sobre ela, em que momento a mulher aparece, se aparece, como aparece e o que tudo isso pode significar.

Pode-se dizer que o método de análise utilizado será o dialético, observando as contradições que existem quando se trata da mulher no livro didático de Geografia. Os livros passam por análises para serem aprovados e distribuídos; pode-se concluir, assim, que seguem minimamente os critérios propostos pelo PNLD 2014. No entanto, quando se analisa os livros com criticidade, percebe-se que essas questões não se encontram suficientemente ou não são discutidas de forma adequada e, ainda assim, esses livros são aprovados pelo PNLD.

Observa-se que, muitas vezes, nos próprios documentos oficiais, há predominância de um discurso construído no masculino, que invisibiliza a mulher. No documento BNCC (Base Nacional Comum Curricular), a palavra "homem" é utilizada em um sentido supostamente neutro para se referir a humanidade; ao mesmo tempo, o documento pede a inserção da discussão do papel da mulher. A LDB também emprega "homem" em sentido neutro, além de não mencionar a palavra "mulher" nenhuma vez no decorrer de todo o seu texto. No PCN para o Ensino Médio a palavra "homem" também é empregada no sentido neutro, e não apenas esta palavra é usada no sentido neutro como ela aparece no documento 19 vezes e a palavra mulher não aparecendo nenhuma só vez. O PCN do Ensino Fundamental também não fica atrás, tento em seu corpo textual a palavra homem escrita 64 vezes, contra apenas 4 vezes a palavra mulher.

Esse levantamento pode ser uma parte do retrato do que estamos lidando, pois a predominância da palavra "homem" não é todo o problema, pois as palavras geralmente quando possuem gênero, estão no masculino. Um exemplo é a chamada do Guia do PNLD 2017 que é: "Prezado colega professor", sendo que, segundo o MEC (anexo 1) a maior parte de docentes da área da educação básica é composto por mulheres, então se a chamada fosse para representar um gênero, deveria ser o gênero feminino. 
Gráfico 1 - Professores das Etapas da Educação Básica segundo o Sexo - Brasil 2007

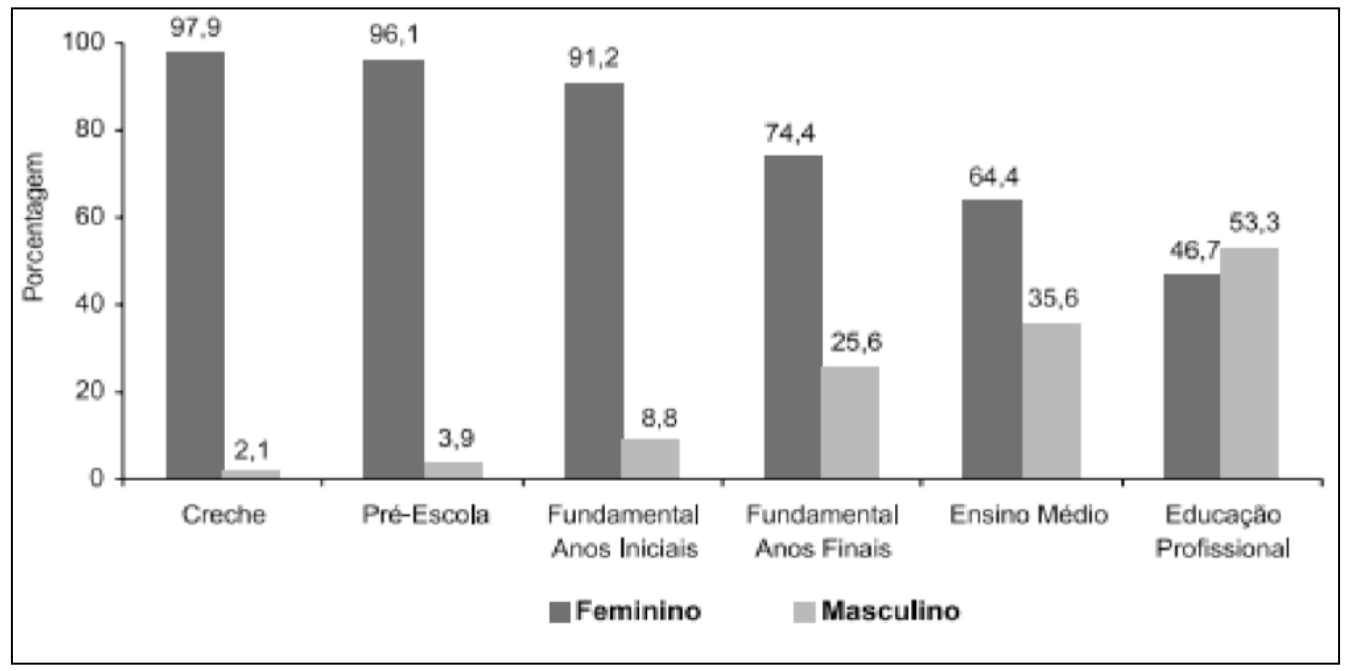

Fonte: MEC/Inep/Deed.

Moreno (1999, p.16) afirma que: “[...] A linguagem reflete, assim, o sistema de pensamento coletivo, e com ele transmite uma grande parte do modo de pensar, sentir e atuar na sociedade". Completando com "As palavras denominam as coisas, mas também fazem com que as agrupemos de uma determinada maneira em nosso pensamento." Concluindo assim que a palavra carrega uma carga significativa, a utilização dela também, sendo assim quando enxergamos apenas referencias e pronomes masculinos, carregamos a ideia de um mundo masculino, de caráter excludente e androcêntrico, de um universo pertencente ao homem. Carregando com naturalidade a ideia do feminino como secundário.

A imagem como linguagem também traz formação de pensamento. Como afirma Ginity (2015)

É notório que a sociedade atual é visual e se o aluno vê aquela imagem sem ser analisada e interpretada sob diferentes pontos de vista, tem como real e verdadeiro aquilo que está posto. Assim, diferentes formas imagéticas de como homens e mulheres são representados contribuem para estabelecer o que cabe a cada um, reforçando a desigualdade de gênero. (2015, p.930)

Ou como discute BERNARDELLI (2015)

"Entendemos que as imagens contidas nestes livros podem ser a primeira referência visual do contexto histórico dos fatos na sociedade, o que aconteceu, o que acontece e o que pode acontecer estão estampados nas páginas dos livros e acabam por influenciar no entendimento das ocorrências, o que pode se tornar mais preciso se a situação for pensada e transmitida da mesma forma pelo professor.” (2015, p.2377) 
Estabelecidas essas discussões, partiremos para a exposição do que foi encontrado nos livros didáticos de Geografia. Dada à exposição faremos a discussão da relevância de tais dados diante do que já foi discutido e com novas problemáticas dentro da discussão.

O Projeto Araribá - Geografia foi o mais distribuído segundo PNLD 2014, foram 3.333.109 a quantidade de livros didáticos de Geografia. Expedições Geográficas foi a segunda coleção mais distribuída, totalizando 1.771 .873 livros pelo Brasil.

Os livros analisados foram dos $7^{\circ}, 8^{\circ}$ e $9^{\circ}$ anos, das duas coleções. Os livros de $6^{\circ}$ ano não foram encontrados, com isso não foram analisados. Também foi pensando que tipo de conteúdo presente no livro (físico-naturais) não seria de grande ausência para a pesquisa.

Foram observadas e quantificadas três categorias no decorrer dos livros. A primeira é a quantidade de vezes que a figura da mulher aparece (seja por foto, por quadrinho ou ilustrações representativas), a quantidade de vezes a figura do homem aparece, usando os mesmos critérios e a quantidade de vezes que a imagem das duas aparecem juntas. A segunda é sobre as citações de trechos de obras no decorrer dos livros, separando da mesma forma, quantas de mulheres, quantas de homens e quantas mistas. A terceira é sobre um adendo que aparece nos dois livros, que são sugestões de leituras. No projeto Araribá - Geografia o tópico aparece com o título: "Para Ler" e no Expedições geográficas com o título: Quem lê viaja mais"

\section{Projeto Araribá Geografia:}

Imagens, citações e indicações de leituras dos livros da coleção Projeto Araribá

Geografia (2014)

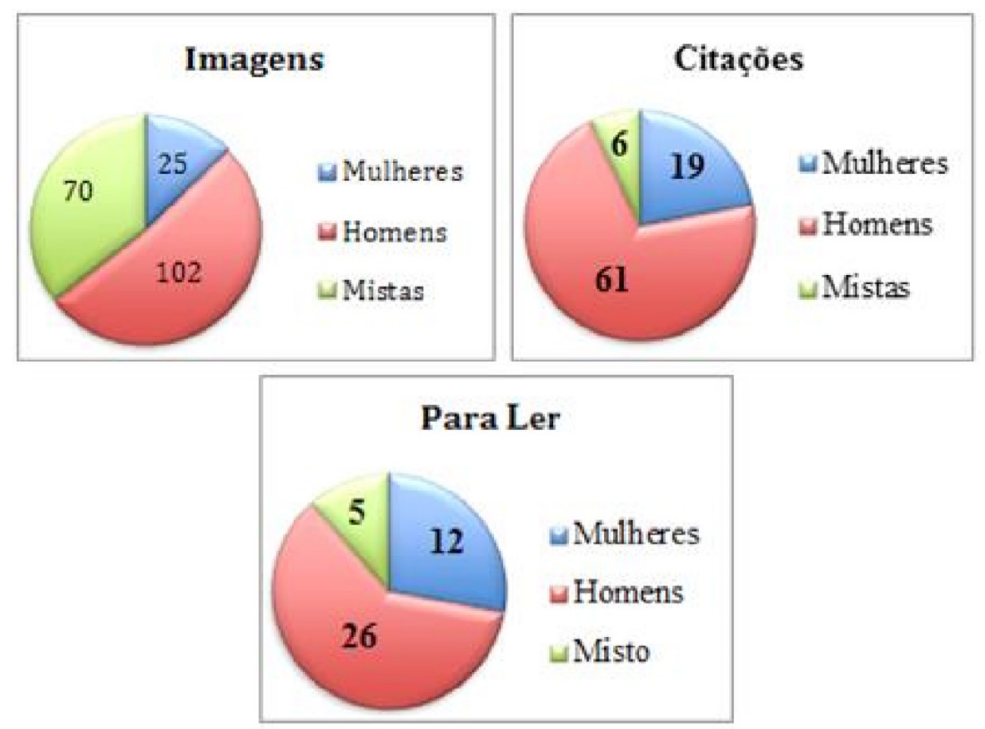




\section{Expediçóes geográficas:}

Araribá

Imagens, citações e indicações de leituras dos livros da coleção Projeto

Geografia (2014)

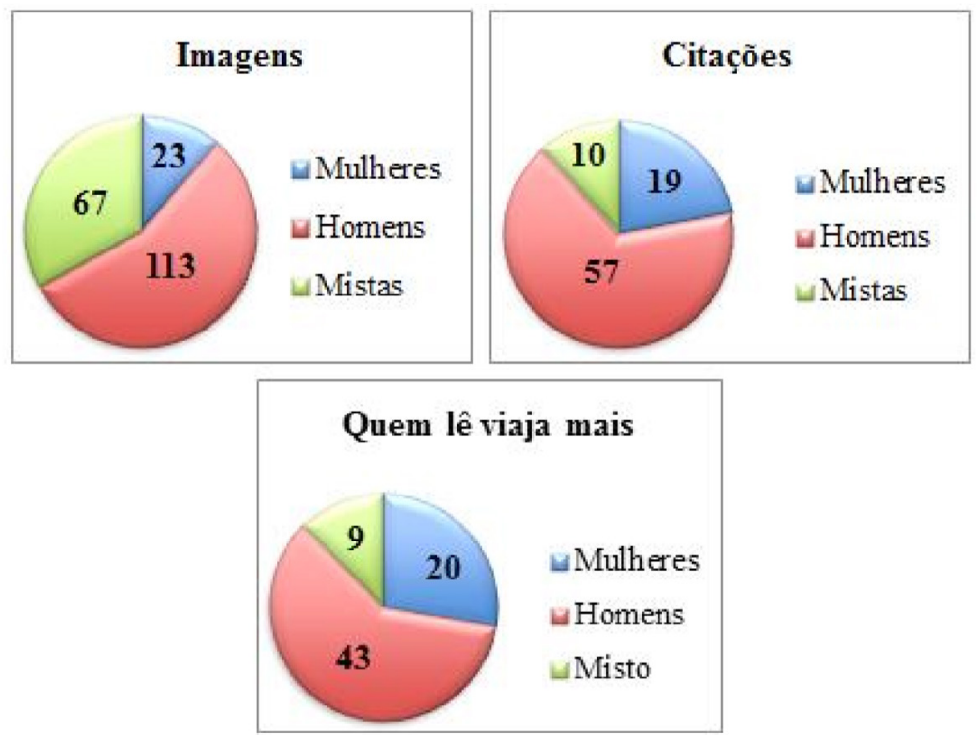

Observando estes dados percebemos que precisamos urgentemente falar sobre mulheres nos livros didáticos de Geografia. Suponho que os gráficos já deixam transparecer o tamanho da discrepância quando se trata da aparição da mulher no livro didático de Geografia. As mulheres ocupam cerca de apenas 25\% de representações nestes livros, sendo apenas cerca de 13\% de imagens somente femininas, mesmo que na verdade, no Brasil ela é cerca de mais da metade da população.

Outro fator que também deve ser levado em conta além da quantidade de vezes que a mulher de alguma maneira é colocada no livro é a qualidade da representação que lhe está sendo dada. As imagens das mulheres nesses livros, não estão em figuras de poder, não estão em empregos qualificados, não estão em um patamar de igual com o restante das representações masculinas. (A igualdade já não se vê desde o momento que apenas o gênero masculino é representado na escrita, como já foi discutido anteriormente).

A imagem da mulher é geralmente algo ligado à maternidade, a trabalhos pouco valorizados, em fabricas de tecelagem ou em algum serviço de manufatura, a situações econômicas desfavoráveis. Durante este texto falamos mulher, mas podem entender mulher branca, heterossexual e cis. A mulher negra pouquíssimo aparece e quando aparece é geralmente em uma situação ou muito aleatória ou pouco favorável. Nas imagens mistas as mulheres estão majoritariamente em 
segundo plano e em alguma situação familiar. Para análise retiramos algumas imagens dos livros didáticos

As oito imagens selecionadas e expostas aqui no texto foram escolhidas para ilustrar o lugar que a mulher representa nos livros didáticos analisados. As imagens 1,4 e 7 demostra como a mulher geralmente é posta nas iconografias ou até mesmo nas fotos em meio a outras pessoas, sendo elas a minoria ou apenas a única pessoa do sexo feminino, e quando as imagens trazem as mulheres usualmente é sempre com um para retratar uma situação de família, ligado a maternidade, sendo assim a mulher nunca está sozinha e com função de representar ela mesma, mas sim o que ela pode gerar: as crianças.

A imagem 2, representa o que já expus aqui, que a mulher quando possui sua imagem reproduzida é associada a alguma posição inferior, a mulher negra sofre ainda mais com este fato, é raramente representada e quando é está em situação desfavorável, como a imagem 2 nitidamente exacerba, uma situação de pobreza e fome.

As imagens 3, 5 e 6 demostram como as mulheres são representadas quando se trata de trabalho. São trabalhos pouco valorizados e mais manuais, como agricultura, artesanato ou trabalhos em indústrias. Cargos de poder e prestígio social, raramente são representados. Os livros abordam em seu texto o tema mulher e trabalho, explicitando que elas geralmente são pouco valorizadas, mas quando selecionam as imagens que estarão em suas paginas não fazem questão de demostrar que as mulheres também possuem papeis importantes e de poder, no quesito trabalho.

A imagem 7 vem ao encontro com todos os fatores, a representação do lugar da mulher como tão pouco importante, que até mesmo na legenda da própria foto, é invisibilizada, com a legenda no gênero masculino, mesmo possuindo uma mulher e uma criança do gênero feminino. Além de a foto reproduzir novamente a ideia da mulher unicamente ligada à maternidade está mais uma vez em situação de pouco prestígio e empoderamento.

Aparentemente os quesitos que estão no PNLD 2014 estão sendo ignorados cinicamente, a menos que "promover a imagem da mulher" seja colocar 12 fotos femininas em cada livro da coleção e seguir em frente afirmado que estas fotos são representativas e empoderadoras.

Saindo um pouco da pauta imagem e indo para referências, as mulheres são minimamente referenciadas. As mulheres claramente produzem conteúdos geográficos e conteúdos de qualidade, mas mesmo assim mais da metade das referências são masculinas (juntando aqui as referências de citações e de indicações para leitura).

$\mathrm{Na}$ coleção Expedições geográficas em todo final de unidade existe um espaço intitulado de "Desembarque em outras Viagens" que basicamente é falando de algum feito importante para as ciências ou artes, em todos os livros analisados não existiu um tópico desses falando de uma mulher. Como se as mulheres ao longo 
da história não tivessem tido nenhum feito de tamanha importância que mereça estar entre os tópicos. Nesta mesma coleção em um dos livros abordou o assunto violência contra mulher, como proposto pelo PNLD. Mas pensamos que é uma ou duas página discutindo questões de gênero e outras oitocentas invisibilizando o que não está no padrão, homem, branco, cisgênero e heterossexual.

Os infográficos praticamente nunca representam uma mulher, quando representam é geralmente por não ter como deixar de representar, porque se trata novamente de maternidade. Deixando aqui a dúvida que se até hoje as mulheres só possuem este papel, o lar, ou como atualmente está popular em dizer, para ser "bela, recatada e do lar", pois sendo um tanto quanto petulante, podemos realmente dizer que o que os livros didáticos analisados trouxeram foi justamente essa mensagem, que o papel da mulher realmente é esse.

Para análise do texto escrito, foi selecionada apenas uma série de cada coleção, podendo assim fazer uma análise mais profunda e complexa do conteúdo disposto no livro didático. A série selecionada é a de $7^{\circ}$ ano, já que é nesta que o Brasil está mais presente, e consequentemente, a realidade e o cotidiano das estudantes.

No livro da coleção Expedições Geográficas em sua apresentação faz a chamada das estudantes no gênero masculino, já apresentando para quem os livros foram escritos, para alunos do sexo masculino. Em todo o texto da apresentação, como podemos presumir está no gênero masculino. $\mathrm{O}$ corpo textual de todo o livro também está seguindo esta lógica sexista.

O livro aborda a temática mulher em dois momentos: quando se trata de natalidade e quando aborda a temática trabalho. Um fator positivo, neste livro é o fato de não atribuir a queda da natalidade no Brasil somente a mulher mas ao casal, detalhe que frequentemente é negligenciado. No tópico sobre trabalho, o livro didático aborda questões como a entrada das mulheres no mercado de trabalho, a desigualdade salarial, o avanço da escolaridade feminina e o aumento de mulheres chefes de família. Apesar de abordar todos estes temas, a discussão de gênero, feminismo, empoderamento feminino é quase imperceptível, o livro apresenta estes assuntos sem problematizar ou aprofundar, fazendo com que ele seja aprovado no PNLD e podendo assim ser amplamente distribuído.

No Guia de Livros Didáticos PNLD 2014 a coleção possui a seguinte análise:

[...] não há uma valorização mais destacada do papel da mulher, do índio e do negro nesse processo. Isso também ocorre quanto aos preconceitos. A coleção promove poucos debates a esse respeito, embora esteja isenta de preconceitos ou indução a preconceitos, relativos às condições regionais, econômico sociais, étnicas, de gênero, de religião, de idade, ou outra forma de discriminação. (2014, p.24)

Outro problema deste livro didático está na legenda das fotos, além de já possuir numericamente menos fotos femininas que masculinas $(7$ femininas, 35 masculinas) e estas fotos não serem representativas e empoderadoras, algumas de suas legendas estão no gênero masculino mesmo quando se trata de imagens de apenas mulheres. 
No livro da coleção Araribá Geografia, em sua apresentação o texto está no gênero masculino, no entanto não se refere a estudante no gênero masculino, como no outro livro analisado, a estudante é tratada por "você" não precisando assim demonstrar o gênero da interlocutora. Coloco o texto como no gênero masculino, pois usa a palavra "professor" e "os colegas".

O texto do livro como um todo também está no gênero masculino, aborda a temática mulher quando se trata de natalidade e trabalho. Quando se fala sobre natalidade, traz o termo

"filho por mulher" e não "filho por casal" como o livro da outra coleção analisado. Sobre o trabalho a mulher entra na discussão no quesito desigualdade salarial, quantidade de trabalhadoras em relação aos homens, a desigualdade hierárquica nos trabalhos em relação ao gênero e desrespeito aos direitos relacionados à maternidade.

Estes elementos que estão relacionados à discussão sobre gênero, novamente não são aprofundados e discutidos, são apenas citados para que a norma do PNLD seja cumprida. A avaliação deste livro pela $\operatorname{PNLD}$ (2014, p.10), no quesito mulher é: "[...] Dá visibilidade ao papel social e produtivo da mulher, discute as implicações do envelhecimento da população e propõe reflexões sobre questões ambientais e de cidadania.".

Os dois livros avaliados não se isentam de crítica ou aprofundamento de outras questões, os dois possuem abordagens críticas e aprofundadas sobre a maior parte das discussões apresentadas, mas quando se trata de gênero a discussão se atrofia.

Estes livros traçam uma história homogênea em relação ao gênero, abordam a chegada dos portugueses e se esquecem da chegada das portuguesas, discorrem sobre a captura dos índios, mas das índias não se fala, debate sobre as desigualdades socioeconômicas omitindo as desigualdades socioeconômicas entre os gêneros, disserta sobre a miscigenação brasileira e esquece como isso começou entre as escravas e senhores de engenho, debate sobre a violência e esquece da violência contra a mulher.

Mulheres e homens ocupam espaços diferentes, se apropriam da geografia de maneira desigual, atualmente, podem até se aproximar na forma em que fazem Geografia, no entanto, no decorrer da história ocidental a discrepância dos espaços femininos e masculinos eram cada vez maiores, portanto não devemos possuir um livro didático contanto apenas um lado da Geografia.

\section{Consideraçóes finais}

O artigo foi escrito no gênero feminino para que haja uma estranheza e consequentemente uma reflexão, do por que existe este incômodo ao lermos palavras no feminino e não existe esta mesma estranheza ao lermos no masculino, ou seja, para atentar-se ao sexismo presente em nossa língua. $O$ gênero masculino não é neutro, a própria palavra já explicita que é masculino. A palavra quando 
colocada no gênero masculino possui uma carga, pode ser a carga que já estamos familiarizadas, porém é uma carga machista e excludente. Mesmo quando o público falado é de maioria feminina, os gêneros das palavras não mudam, no entanto, em meu texto, tentei trazer esta mudança, até porque se formos acompanhar a maioria, a maior parte da população brasileira é de mulheres. Esta explicação não foi colocada no início do texto para que a leitora refletisse sem ser avisada do intuito da reflexão, e consequentemente não influenciasse em suas conclusões.

A representatividade da mulher nos livros didáticos analisados é insatisfatória, pois percebe-se que o espaço dedicado às mulheres, quantitativamente, é irrisório em relação ao espaço dedicado aos homens; qualitativamente, esse espaço é insuficiente, já que não representa a mulher no texto escrito, no discurso, nem em imagens, ou especializações, citações ou nos quadros dedicados a sugestões de leituras. A presença da mulher nestes elementos, quando ocorre, geralmente não é de cunho crítico e reflexivo e sim de repetição do senso comum. A mulher que está presente nestes livros didáticos é uma mera reprodução das ideias que comumente estão ligadas à mulher. Os livros não trazem uma representação verdadeira de mulheres e de suas possibilidades.

Todo este trabalho poderia girar em torno de apenas um dado: apenas 13\% das imagens desses livros didáticos são de mulheres. Quando destaca-se esse dado, percebe-se a dimensão do problema com o qual lidamos. Ao pensar que apenas $25 \%$ das representações, de forma geral, são de mulheres, também é possível mensurar a problemática e questionar como esses livros podem ser os mais distribuídos no Brasil, e quais consequências isso pode trazer.

Os livros didáticos de Geografia avaliados possuem grandes falhas em relação a presença eficaz da discussão de gênero, contudo estes apontamentos não tiram seu valor como material didático essencial das escolas públicas atuais. O que pretendi, aqui, foi trazer à luz a percepção de que igualdade de gênero no livro didático vai além de dedicar uma página a abordagem de questões ditas de gênero. A proposta foi demonstrar o quanto nós, mulheres, nos encontramos, ainda hoje, em situação de invisibilidade e estamos acostumadas com isso, a ponto de muitas vezes não percebermos que participamos tão pouco de um livro didático que em teoria é unificador e crítico.

O livro didático, no momento, está contribuindo e consonando com os problemas em relação ao gênero. No entanto, ele possui potencial e capacidade para combater e auxiliar na discussão de mulher na escola, na sociedade e na Geografia escolar, basta termos consciência do que estamos consumindo e do que queremos consumir em nossa educação básica.

\section{Referências}

BANDEIRA, Lourdes. Feminicídio: a última etapa do ciclo de violência contra a mulher.

In Revista do Observatório Brasil da Desigualdade de Gênero. p.76, 2014. 
BERNARDELLI, M. A. A construção da feminilidade na imagem fixa da mulher em livros didáticos. In: VII Congresso Internacional de História - XXXV Encuentro de Geohistoria Regional/XX Semana de História da UEM, 2015, Maringá. VII Congresso Internacional de História - XXXV Encuentro de Geohistoria Regional/XX Semana de História da UEM - ST: 14: História e Relações de Gênero: reflexões em pauta. Maringá: CIH/PPUEM, 2015. p. 2369-2381.

BITTENCOURT, C. M. F. Apresentação da seção Em foco: História, produção e memória do livro didático. Educação e Pesquisa, set./dez. 2004, v.30, n.3, p.471-473.

BRASIL, Governo do. Mulheres na política. Disponível em: < http://www.brasil.gov. br/cidadania-e-justica/2012/02/mulheres-na-politica>. Acesso em: 1 out. 2017.

BRASIL. Parâmetros curriculares nacionais: terceiro e quarto ciclos: apresentação dos temas transversais. Brasília: MEC/SEF, 1998.

CONTI, J. B. A Geografia física e as relações sociedade/natureza no mundo tropical. São Paulo: Humanistas FFLCH/USP, 1997.

CPMI-VCM, Comissão Parlamentar Mista de Inquérito sobre Violência contra a Mulher Relatório Final, CPMI-VCM, 2013.

FERNANDES, F. A Contestação necessária: retratos intelectuais de inconformistas e revolucionários. Ática: São Paulo, 1995.

GINITY, Eliane Goulart Mac. Imagens de mulheres nos livros didáticos de história. In: Revista do Lhiste, Porto Alegre: num.3, vol.2, jul/dez. 2015.

IBGE: Pesquisa Nacional por Amostra de Domicílios: Síntese de Indicadores 2014. Disponível em: http://biblioteca.ibge.gov.br/visualizacao/livros/liv94935.pdf.

IPEA, Instituto de Pesquisa Econômica Aplicada. . Disponível em Brasília: Ipea, 2013.

JAPIASSU, Hilton. O Mito da Neutralidade Científica. Rio de Janeiro: Imago Editora, 1975.

LINHARES, Juliana. Marcela Temer: bela, recatada e "do lar". Revista Veja, 2016.

Disponível em: < https://veja.abril.com.br/brasil/marcela-temer-bela-recatada-e-dolar/>. Acesso em: 01 dez. 2016.

MARTÍNEZ, Ana S., MOYA, Juana R. e MUNOZ, M. Mujeres, Espacto y Sociedad Hacia una Geografía del Género. Madrid: Síntesis, 1995.

MARTINS, Isabel. Analisando livros didáticos na perspectiva dos Estudos do Discurso. Proposições, Sao Paulo, v. 17, n. 1, p.118-136, 2006.

MOVIMENTOMULHER360. MM360 explica os termos gaslighting, mansplaining, manterrupting e bropriating. Disponível em: <http://movimentomulher360. 
com.br/2016/11/mm360-explica-os-termos-gaslightingmansplaining-bropriating-emanterrupting/>. Acesso em: 30 nov. 2017.

MORENO, Montserrat. Como se ensina a ser menina: o sexismo na escola. (Trad. Ana Venite Fuzatto). São Paulo: Moderna, 1999.

ONU: Taxa de feminicídios no Brasil é quinta maior do mundo; diretrizes nacionais buscam solução. Disponível em: <nacoesunidas.org/onu-feminicidio-brasil-quinto-maiormundodiretrizes-nacionais-buscam-solucao>. Acesso em: 01 de outubro de 2017.

SILVA, S. M. V. Geografia e Gênero/Geografia Feminista - O que é isso? Boletim Gaúcho de Geografia, 1998.

\section{Anexos}

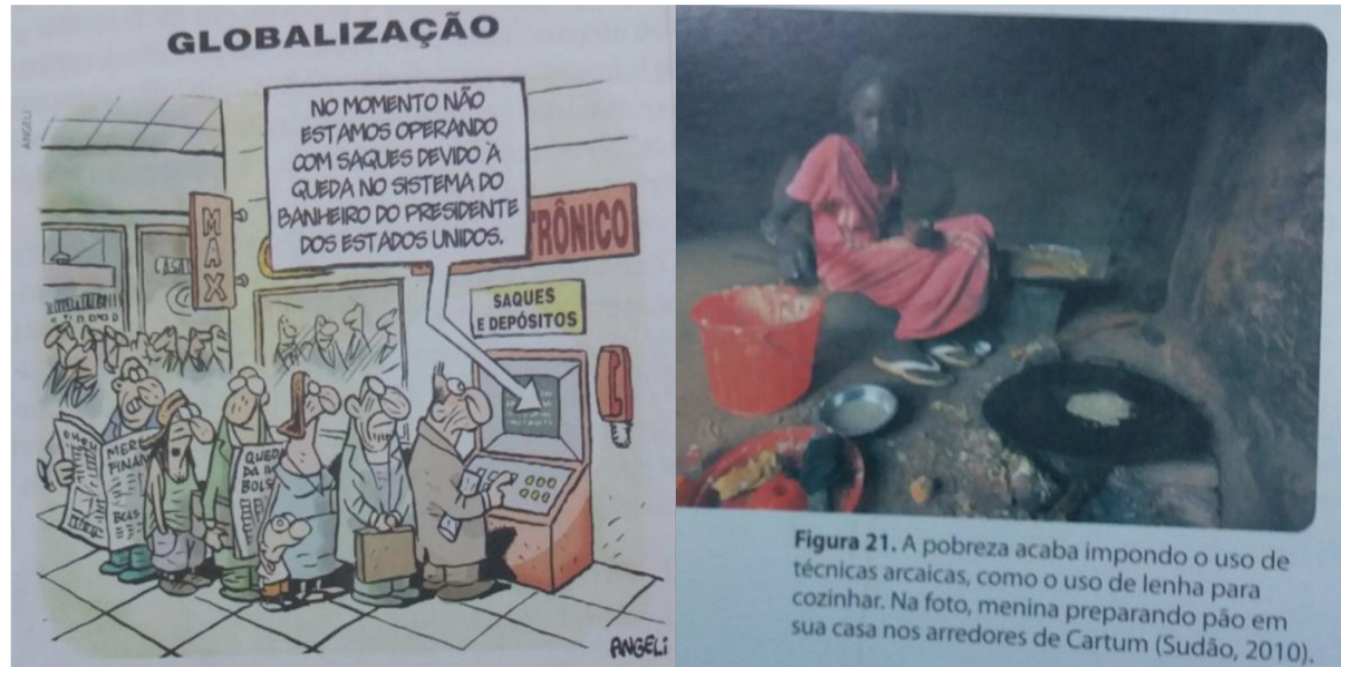

Imagem 1

Imagem 2 


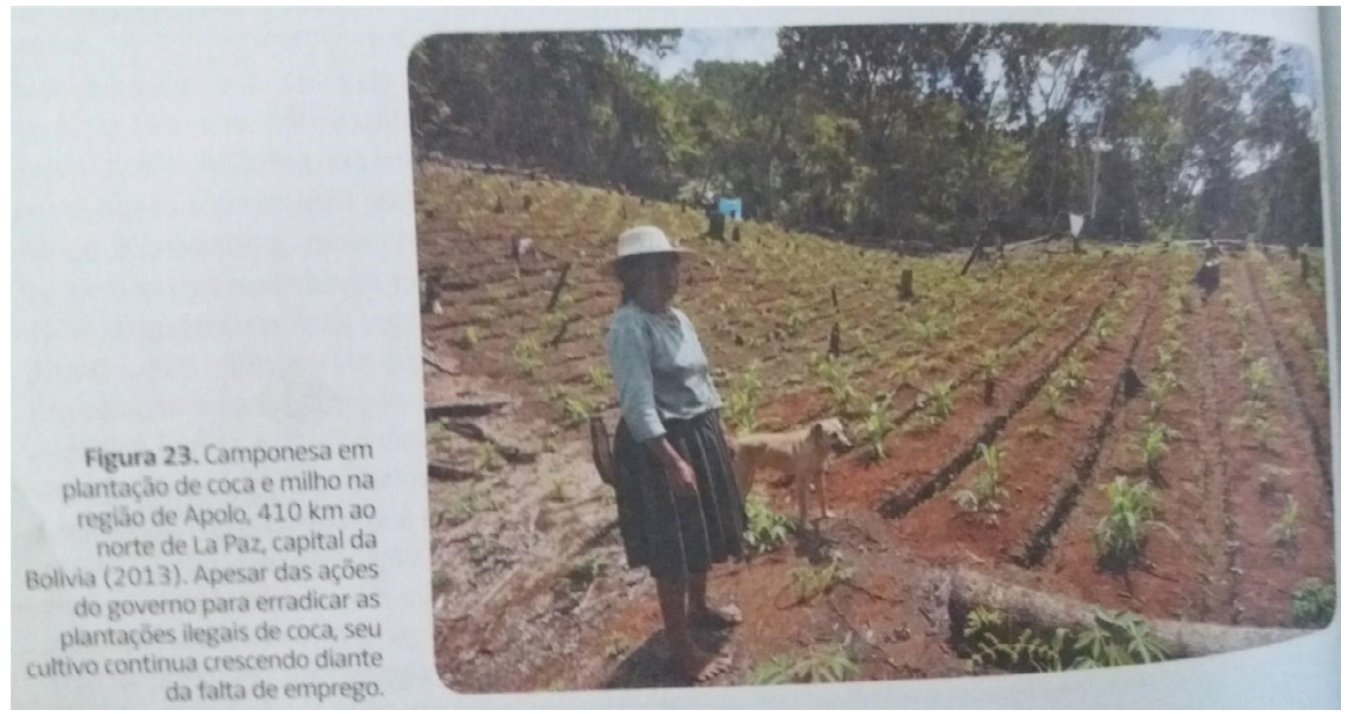

\section{Imagem 3}

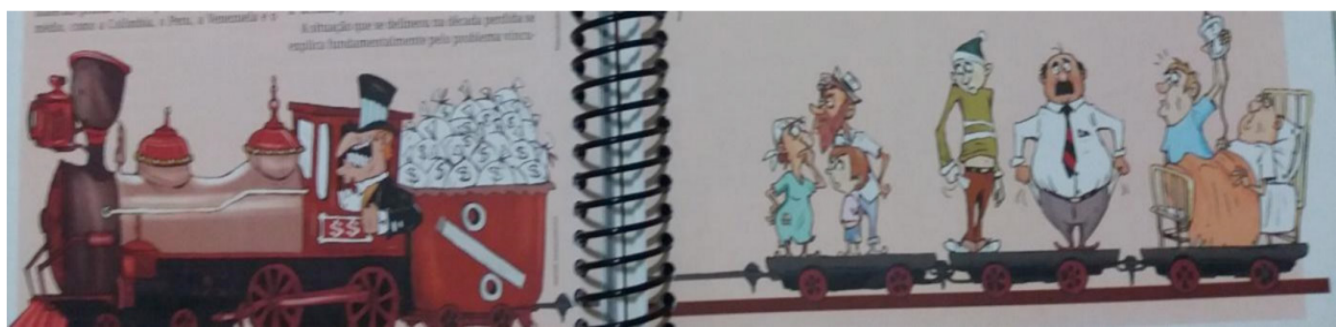

\section{Imagem 4}
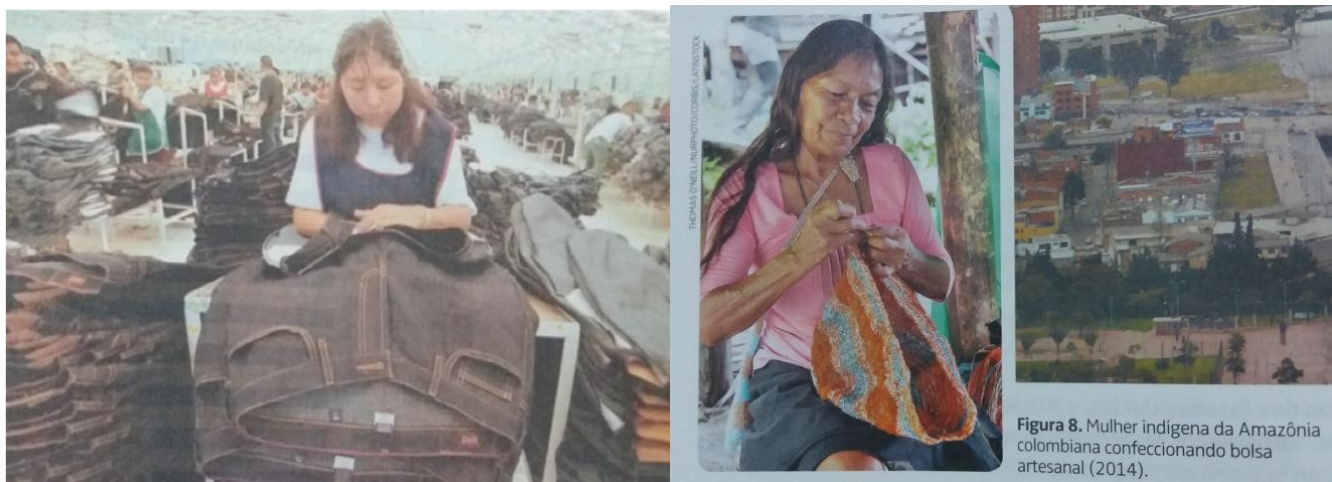

Imagem 5

Imagem 6 


\section{Uma populaçāo cada vez mais diversificada}

Cada vez mais a populaçăo dos Estados Unidos se diversifica. Ja em 2003. o tamanho da comunidade hispânica (imigrantes de paises de língua espanhola e descendentes) vivendo no país superou o de afro-americanos graças à imigraçăo e

maior taxa de natalidade desse grupo. O Centro de Pesquisas Pew estima que até 2050 a população branca năo hispânica deixará de ser maioria absoluta no país. Veja no infográfico a seguir quais sâo as projeçōes para a população estadunidense. Hispánicos shlo a principal minoria" Participacto dos grupos na populaço dos Estados Unidos, atual e projetada
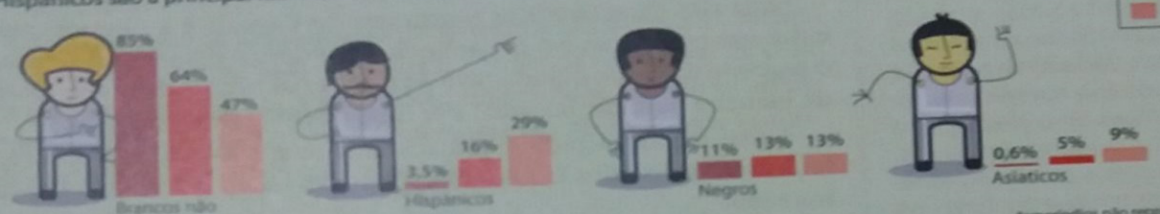

Wats comuns dot Estados Unidos Ocomencis do sobrenome (por 100 mill pessoasi) Unietas a presca cada vez muigr de sobrencmes de origem

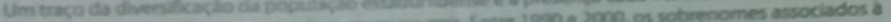

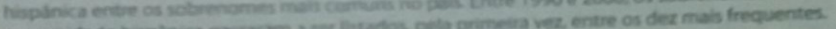

cominidade hesplnica posisaram a ser lihtados pelo primedra vez,

\section{SMITH JOHNSON} WILLIAMS JONES BROWN DAVIS MILLER WILSON MOORE TAYLOR ANDERSON THOMAS JACKSON WHITE HARRIS MARTIN THOMPSON GARCIA MARTINEZ ROUINSON CLARK RODRGUEZ LWWS LI WALIR

\section{$\operatorname{Em} 2000$}

\section{SMITH JOHNSON} WILLIAMS BROWN JONES MILLER DAVIS GARCIA RODRIGUEZ WILSON MARTINEZ ANDERSON TAYLOR THOMAS HERNANDEZ MOORE MARTIN JACKSON THOMPSON WHITE LOPEZ

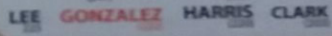
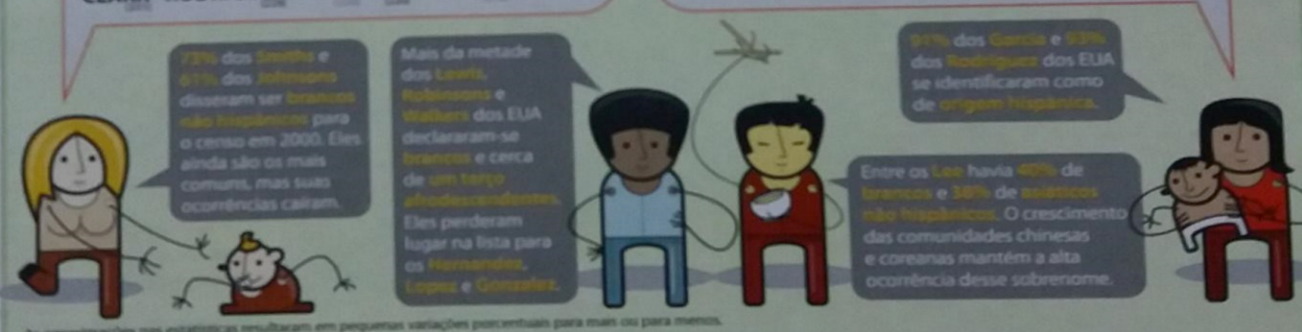

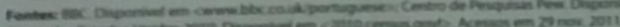

\section{Imagem 7}

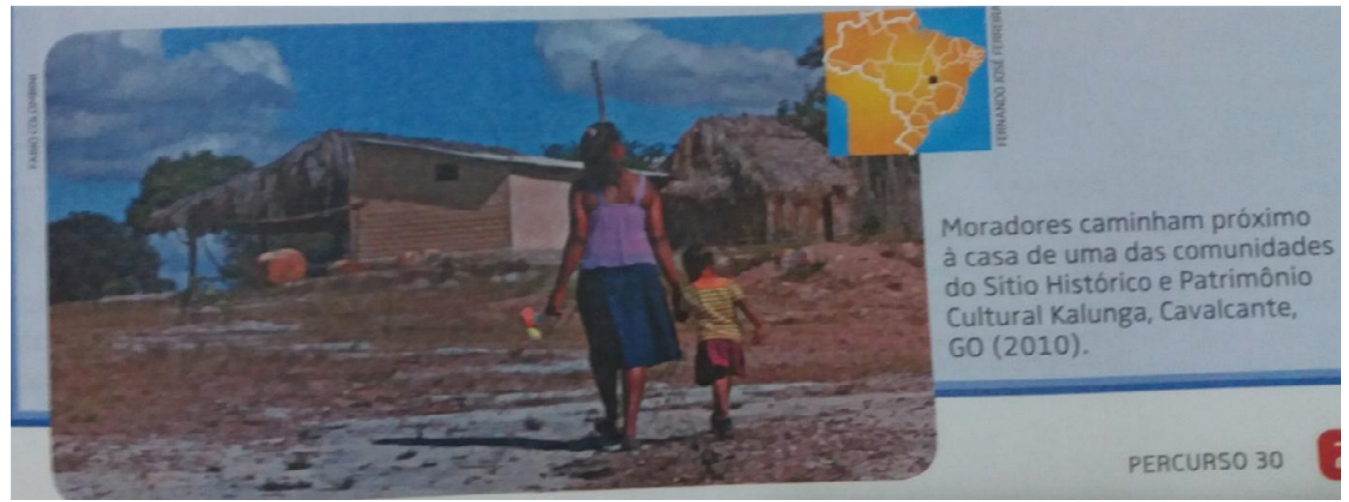

Imagem 8 